\title{
Effect of four soil and water conservation practices on soil physical processes in a non- terraced oil palm plantation
}

\begin{abstract}
Mulching materials from oil palm residues such as pruned palm fronds (OPF), empty fruit bunches (EFB), and Eco-mat (ECO; a compressed EFB mat) are often the recommended soil and water conservation practices $(\mathrm{CP})$ for oil palm plantations on hill slopes. Another recommended CP is the construction of silt pits or trenches (SIL) across the hill slope to capture runoff and then return the water and nutrients into the surrounding soil. Although these four $\mathrm{CP}$ are recommended practices, their relative effects on improving soil physical properties and on increasing the soil water content have never been compared with one another. Consequently, the objective of this study was to fill in this knowledge gap. A threeyear field experiment was conducted in a non-terraced oil palm plantation, and soil samples from 0 to $0.15,0.15$ to 0.30 , and 0.30 to $0.45 \mathrm{~m}$ depths were collected every three months and analyzed for their soil physical properties. Soil water content up to $0.75 \mathrm{~m}$ depth was also measured daily. EFB released the highest amount of organic matter and nutrients into the soil compared to OPF, ECO, and SIL. Hence, EFB was most effective to increase soil aggregation, aggregate stability, soil water retention at field capacity, available soil water content, and the relative proportion of soil mesopores. Due to these improved soil physical properties, EFB also gave the highest soil water content. Unlike ECO that concentrated more water in the upper soil layers, EFB distributed the soil water more uniformly throughout the whole soil profile, but SIL concentrated more soil water in the lower soil layers $(>0.30 \mathrm{~m})$ because the water levels in the pits were often below $0.30 \mathrm{~m}$ from the soil surface. The large opening area of the silt pits could have also caused large evaporative water losses from the pits. EFB mulching is recommended as the best $\mathrm{CP}$, particularly for oil palm plantations on hill slopes.
\end{abstract}

Keyword: Empty fruit bunches; Eco-mat; Silt pit; Oil palm fronds; Mulch; Hill slope; Organic matter 